\title{
Online Shopping Behavior of Bangladeshi People
}

\author{
Fabiha Enam Tanjila Rahman Mehedi Hasan Tanvir \\ BRAC Business School, BRAC University, 66 Mohakhali, Dhaka 1212, Bangladesh
}

\begin{abstract}
Bangladesh as a developing country has been seeing a lot of dependence in digital money transaction with which people's habit of Online shopping is increasing furthermore. To understand people's shopping behavior more concretely we went ahead and did a research on it. The main incentive of the research is to find out the shopping behavior of the people in Bangladesh and the kind problem that people are generally facing that is working as a discouraging factor. For this reason, a structured and closed ended questionnaire was used on a random sample population to know the behavior of the people regarding online shopping. From the answers of those questions, it is found that, the 18-23 years old people do the online shopping most. Moreover, male persons are more likely to do shopping on online than the female group. For shopping, most of the people use "Facebook Pages" according to our research. Here, many people are also unaware of the apps that the online shopping service provider provides. Not only that, most purchased items on online is clothing and after that most purchased item is food. While purchasing foods from the online, most people choose "Food Panda". Our survey also found that for buying electronic gadgets most people use daraz.com and evaly.com. Much to our surprise, a lot of people doing online shopping on a regular basis feel quite secured on the platform. However, most people think that online services need to be improved and we saw a lot of complains about the displayed or descripted product not matching the actual product. Moreover, they are also unhappy with delivery service that online service providers provide to the customer. The most alarming part that we found out through our survey is many people are taking online shopping service but the frequency is too low, which is once in a month. Another major complain about online shop is delivery issues. Most of the cases it seems that delay in delivery for products create lot of problem for customers. Keeping all those behaviors and dissatisfactions of the consumer in our mind, we have tried to recommend some strategy to the online service provider to remove those dissatisfactions among the people. If these issues and problems like these can be resolved, more people might accept the process of Online Shopping and a lot of people might consider doing Online Shopping more frequently. The main objective of this research paper is to understand how people in Bangladesh view the whole platform of Online Shopping, it's perks and problems and how it can be improved more to attract more in order to attract more people toward the platform.
\end{abstract}

DOI: $10.7176 / \mathrm{EJBM} / 12-6-05$

Publication date: February $29^{\text {th }} 2020$

\section{Introduction to Study}

Online shopping is getting much popular with advancement of technology around the world. Bangladesh has much potential in this regard. Boston Consulting Group and Telenor have predicted that in few years $32 \%$ families of Bangladesh will have at least one internet connection (Daily observer, $26^{\text {th }}$ June, 2019) [2]. So, this will ultimately make a huge impact on online shopping. According to Brown, Pope and Voges, (2003) online marketplace provides the shoppers an easy access to the information of a brand's product quality, availability, specifications and prices along with comparison with another brand. [3] Moreover, according to Ramisha Haque (2019). E-stores and online trade has left an incredible imprint on e-commerce. [4]. Though many people have started shopping on online due to this technology advancement but still it is not trustworthy to many people in our country. People prefer to use to cash-on delivery option. But the perspective has changed a little bit when Bangladesh Bank launched National Payment Switch Bangladesh (NSPB) which brought every bank into one umbrella for payment systems in December, 2012. So, this paper will show the acceptance level of the people of Bangladesh and its future here.

\section{Objective of study}

This study is constructed to determine the actual scenario of the behavior of people in Bangladesh when it comes to 'Online Shopping'. So, the specific objectives of this study are-

- To find out the behavior of the people in online shopping.

- Finding the preference level between 'Traditional shopping' and 'online shopping'.

- Recommending the effective steps to make 'Online shopping' more popular in Bangladesh.

\section{Limitations of the study}

- The study might not have been able to reach every people like those who are living in village.

- The study does not categorize all people without age and gender. 


\section{Significance of study}

Online shopping is becoming much popular if we compared to $3 / 4$ years back. People can buy anything they want from online. In some specific sectors it's getting more popular than the local shopping as it was mentioned earlier that we have collected data from 135 peoples. There were 12 specific questions regarding the significance of online shopping in Bangladesh and its future. By this study we can see a clear difference from the perspective of consumers if we compared to past. There are a lot of differences behind it. Firstly, shopping online is more convenience. It saves our money and valuable time. Buyers can order anything from online and it will be delivered to his home or work place. Now a days we see that a lot of online shop gives discounts on their products which will lead to more saving for shoppers. There is a good competition in the online selling brands. People can easily compare one brand to other brands within few seconds just visiting their online pages or website and checking their online reviews given by customers. There is a system called pre order. If you have any chosen products which are not available in our country, you can choose pre order options and within few days you can get it from any country. From our data collection it also gets to know that 18-23 age range people are using more online shopping compared to others and most of them are female. Among them $60 \%$ peoples are using Facebook online shop because of more reliable and lot of collection and many more competitors. Furthermore, two most popular segments of products from online shops are food then clothing items. Basically, food is more popular among others because we see that people are getting busier day by day with their work life and other stuffs. If they get the food online instead of going restaurant then why not! There are a lot of options to choose for food delivery online system like uber eats, food panda etc. among them food panda is more popular than others because of faster delivery and constantly maintaining their quality and brand image. After that clothing also hold a big market value for online shopping sector in Bangladesh. Verities of product, uniqueness and reasonable price are the only key behind this big sector. When anyone lends a shop in remote area it will cost a good amount of money. Seller has to charge high for making profit out of it. But for online shops there are big chances to get original price for any product. However, there are a lot of reasons people still does not rely properly on online shops in Bangladesh. From the survey we find lot of negatives review regarding online shop in Bangladesh. Among them major issues are not feel safe about online shopping as many of the time they did not get the match product which they ordered from online. Furthermore, online shopping may expose your credit card to online theft, thereby leading to financial problems. Another major complain about online shop is delivery issues. Most of the cases it seems that delay delivery for products creates lot of problem for customers.

\section{Literature Review}

A research conducted by Tanjila Tabassum (operations and supply chain management, Amercian International University Bangladesh), Tahsina Khan (Marketing, American International University-Bangladesh, Bangladesh) \& Nazia Hasan (Management Information System, American International University-Bangladesh, Bangladesh) o Attitude towards Online Shopping among Urban Bangladeshi Youth: Factor Analysis of the Influencing Parameters. This study shows that the Attitude of consumers play a very important role among the parameters as the variables under the parameter is found to explain the most variability. In other word, the picture they have about online shopping in their mind impacts their decision. Price is the second most significant parameter of the study. The time saving and convenience seeking urban youth of Bangladesh considers price before making a deal on online shopping even they find they convenient (IOSR journal of business and management, e-ISSN:2319. Volume 19, issue8.Ver.VI. (August 2017), pp 42-50). A study conducted by Emon kalian Chowdhury (Assistant professor. department of accounting, faculty of business studies, premier university, Chittagong, Bangladesh) \& Rupam Chowdhury (Lecturer, faculty of business administration, university of science \& technology Chittagong, Chittagong, Bangladesh on online shopping in Bangladesh. This study finds a positive relation between the online shopping stimulators and shopping behaviors of respondents. It also observes that shopping through online extremely popular among the youngsters but it failed to draw satisfactory attention of the mass people particularly old and technologically challenged due to complex purchase process and payment settlement system, lack of reliability, traditional mentality of customers (South Asian Academic Research journals, Vol.7 Issue 4, April 2017). A study conducted by Mohammad Harisur Rahman Howladar, Associate Professor, Department of Management Studies, Chittagong University, Bangladesh, Prof. Madya Dr. Md Golam Mohiuddin, Faculty of Management and Human Resource Development, University Technology Malaysia \& Mohammad Muzahidul Islam, Assistant Professor, Department of Management Studies, Patuakhali Science and Technology University, Bangladesh on Developing Online Shopping Intention among People: Bangladesh Perspective. This study shows that online purchase intention and its continuity depend on attitude of customer that ultimately influenced by trust or belief on online shopping, subjective norms that depend on social and media role, control variables and some support facilities. This conceptual framework provides good theoretical platform for empirical grounded research on electronic commerce in Bangladesh. (Developing Country Studies ISSN 2224-607X (Paper) ISSN 2225-0565 (Online) Vol 2, No. 9, 2012) 


\section{Methodology}

The following study is designed in such a way that we can understand how differently people of different age and gender think of Online Shopping in Bangladesh as of now. To that end, we divided the entire scenario into some discouraging factors such as, Hassles and inconveniences faced during delivery, Security on Online Shopping, Inaccuracy of Actual Products when delivered, : Issues and inconveniences regarding monetary transactions, Availability of information regarding the product and the delivery process and : The entire process and the ease of ordering products. These are all the factors we are considering as Independent Variables upon which People willing to buy online goods and services depend. The research that has been done for this paper was done firstly using a set of questionnaires we created followed up by secondary data from different external resources. The questionnaires are set up to get information from the people about their age, gender and the different issues regarding the Online Shopping scenario. The research questionnaire was circulated to different groups where people of almost all ages participated in. The age distribution we did was divided into 6 parts, Less than 18 years, 18-23 years, $23-30$ years, 30-40 years, $40-50$ years and lastly more than 50 years. With this, we got a general idea about how people of different age think of the Online shopping scenario. We also set up some questions about different issues people are facing when shopping online. Using these, we have come into some conclusions regarding how differently aged people think and what kind of issues most of the users are facing.

\section{Statement of the Problem}

Bangladesh as a rapidly growing country is getting more used to the digital money transaction processes which are leading to more Online Shopping for people in the country. This craze for online shopping is definitely not going to stop anytime soon. People are buying online products and services on pretty much at least a regular basis. According to our questionnaires, roughly $54.6 \%$ people answered that they do online shopping at least once a month and another $26.9 \%$ answered that their pattern of online shopping is at least once a week.

\section{How secured do you feel shopping from online?}

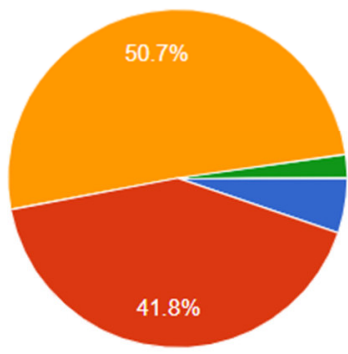

What kind of problems do you generally face while doing Online shopping? 134 responses

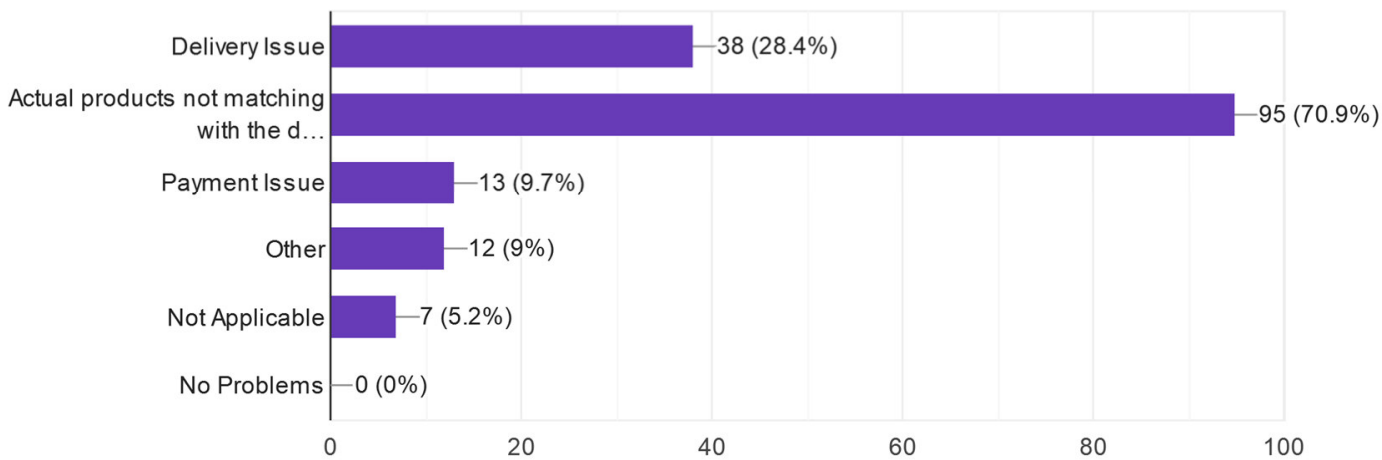


There is no doubt that these numbers are just going to keep increasing. However, this platform of online shopping is not flawless. Through our questionnaires we got answers too about how people face different kind of problems and how often they face it. According to our survey, people have faced a lot of problems in this sector. Not much to our surprise, no one in our survey answered that they did not face any problems during online shopping. Except for 5.2\% of the sample population who went for Not Applicable, everyone faced some kind of problem. Of course, the problems varied from person to person. Some of the problems people mentioned were about how a lot of people think that online shopping is not very secured. Furthermore, a lot of people complained about the delivery hassles and issues they faced in the process too. Almost $71 \%$ of the sample population complained about how the actual products often don't match with the description or the shown picture. Some more issues are about the problematic process of ordering and the lack of information. People also seem to face problems regarding payment. So, people are facing quite a lot of problems when ordering online and if issues and problems like these can be resolved, more people might accept the process of Online Shopping and a lot of people might consider doing Online Shopping more frequently.

\section{Problems:}

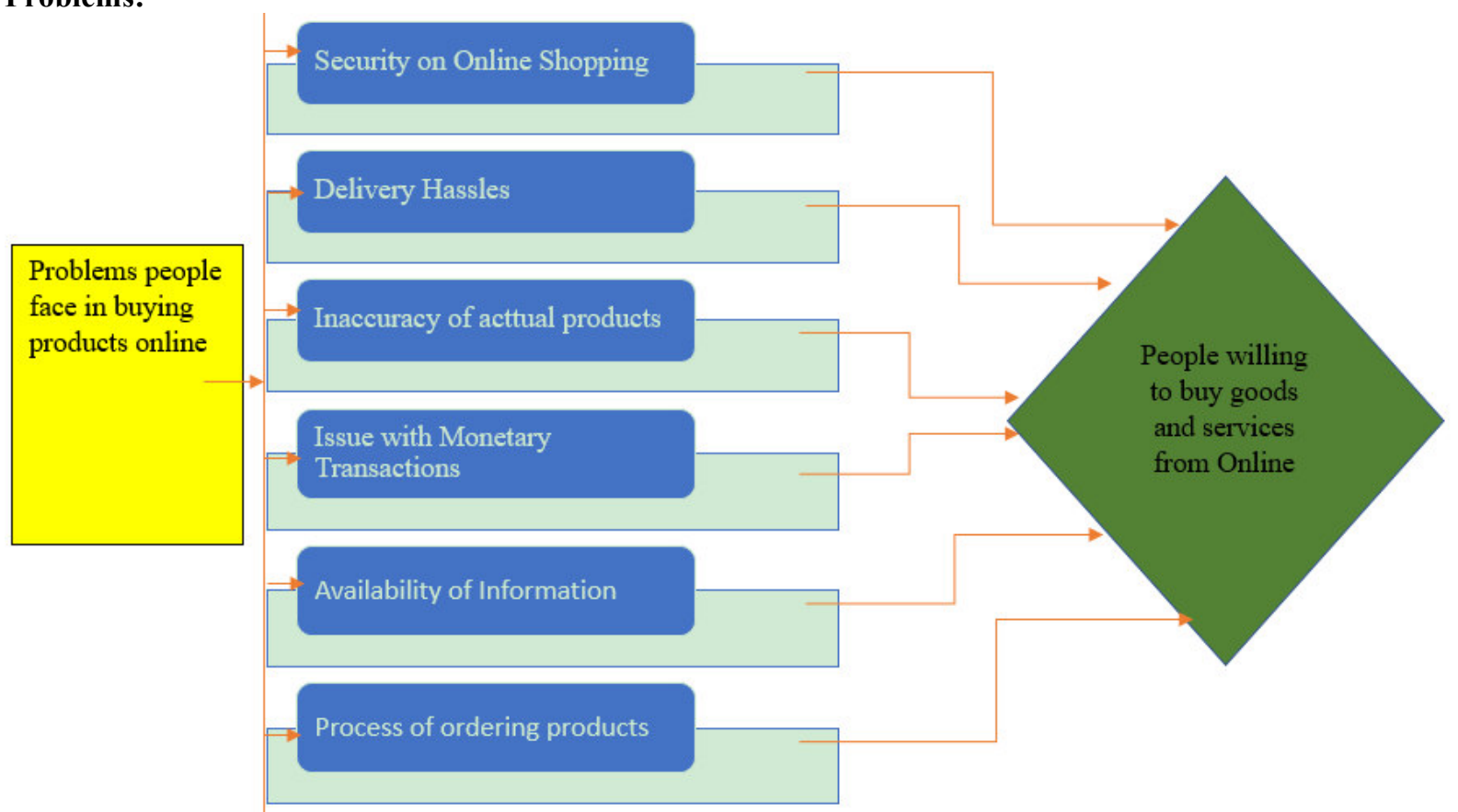

Fig: Problems people face in online Shopping in Bangladesh

\section{Analysis \& Discussion}

For making our research paper on online shopping behaviors of Bangladeshi people, we did a survey on 135 people. There were people of different ages. But for our survey we narrowed down our segment. And we chose to survey on those people whose age limits are 18 -30 years old. We also did survey on others but our main focus was on them. From our survey we got to know that young generations are more addicted to online shopping. And their age limits are 18-30 years old.

What is your age?

135 responses

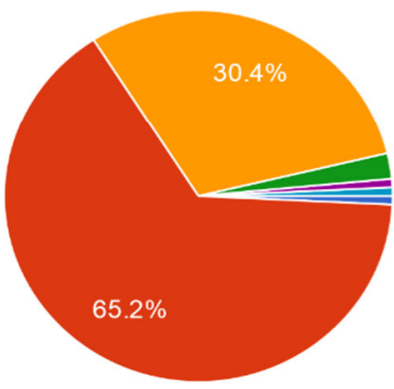

Less than 18 years

$18-23$ years

23-30 years

30-40 years

40-50 years

More than 50 years 
Among them there were $65.7 \%$ people whose age limits were $18-23$ years old and there were $29.9 \%$ people whose age limits were 23-30 years old. Also, male percentages (58.2\%) were more than female percentages $(41.8 \%)$. Here consumers showed their justification about the nine benefits of online shopping, including effectiveness, convenience, information, safety, service, delivery speed, web design, selection, and familiarity with company name. Here we can see that consumer like online shopping but they their rating is high on traditional shopping.

What is your gender?

135 responses

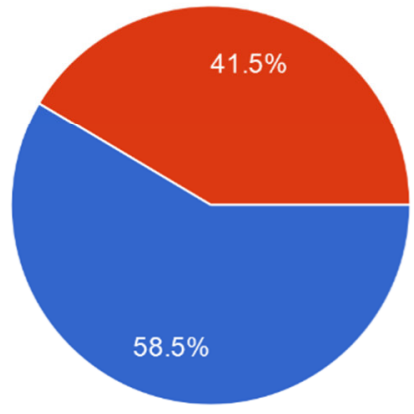

Which platform do you use more regularly for online shopping?

135 responses

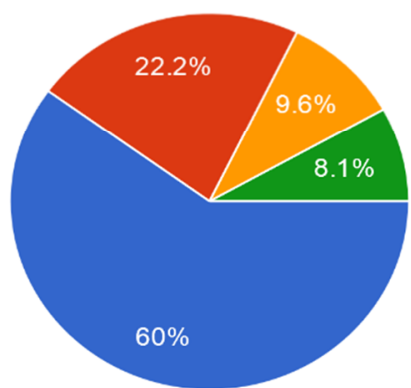

Facebook

App

Phone

Not Applicable

Among 135 people there was $65.7 \%$ people whose age limits were $18-23$ years old and there was $29.9 \%$ people whose age limit was $23-30$ years old. There were $41.8 \%$ female and there were $58.2 \%$ male. About $54.3 \%$ people said that they do online shopping for 4 times a week. And about 27.1\% people said that they do online shopping for once a week. About 59.7\% people said that they use Facebook for their online shopping, about 22.4\% people said that they use app for their online shopping, about $9.7 \%$ people said that they use phone for their online shopping and about $8.2 \%$ people were not sure about it. About $48.5 \%$ people said that they purchase food more frequently from online; about $23.1 \%$ people said that they purchase electronics more frequently from online; about $55.2 \%$ people said that they purchase clothing items more frequently from online. About $6 \%$ people said that they purchase groceries from online. And also, about $6 \%$ people said that they purchase decorations items from online. About $62.7 \%$ people said that they are not so open to buy expensive products from online; about $23.1 \%$ people said they are very open to buy expensive products from online and about $14.2 \%$ people said that they never thought about buying expensive products from online. About $89.4 \%$ people said that the online shopping scene in Bangladesh is not improved enough and about $9.8 \%$ people said that no improvement needed here. About $28.6 \%$ people said, while they are doing online shopping, they face problem with delivery issue, $70 \%$ people said that sometimes actual products did not match with the description or picture and $9 \%$ people said that they faced problem with payment issue. About $50.9 \%$ people said that they are secured with online shopping and about $42.1 \%$ people said they are not very secured with online shopping. About 33.8\% people said online shopping is better than traditional shopping and about $66.2 \%$ people said online shopping is not better than traditional shopping. There are many platforms in online for buying food items. About $44.7 \%$ people said that they use food panda for purchasing food on online, $22.7 \%$ people said that they use Pathao food for this, $12.1 \%$ people that they use UBER Eats and $11.4 \%$ people said about other platforms. So, it is obvious that food panda is a renowned food platform to consumers. For electronics and other items $32.1 \%$ people said that they use evaly.com and also $32.1 \%$ people said that they use daraz.com, $14.5 \%$ people said about ajkerdeal.com and $8.4 \%$ people said about pickaboo.com. So, we can say that Daraz.com and evaly.com are renowned platform for buying electronics and other items. 
Which is your go to platform for buying food items online? 133 responses

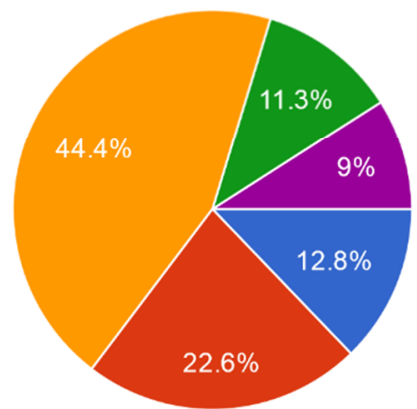

UBER Eats

Pathao Food

FoodPanda

Other

Not Applicable

Which is your go to platform for electronics and other items?

132 responses

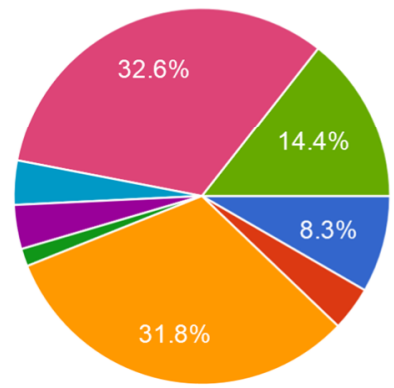

Pickaboo.com

Evaly.com

Daraz.com

AjkerDeal.com

Rokomari.com

Bagdoom.com

Facebook Pages

Not Applicable

\section{Findings}

What type of products do you more frequently purchase from the internet? (Tick 2 products) 135 responses

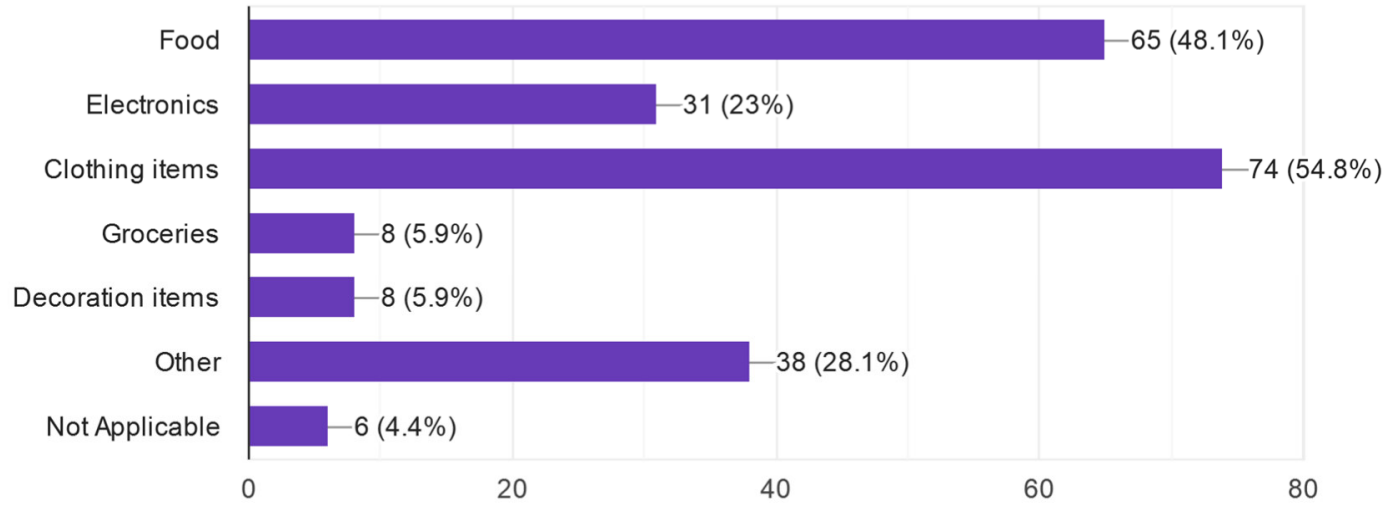

Do you think that Online shopping is better than traditional shopping?

134 responses

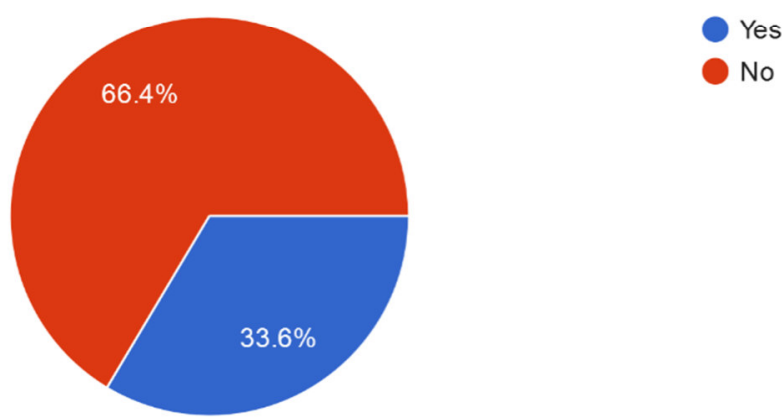

The main objective of the research was to find out the online shopping behavior of people in Bangladesh. There 
were some established hypothesizes on people's behavior about online shopping and checked the hypothesis against the sample questions. According to the findings of the study, most of the people who were involved in the study were young age people among which more than half of them were male and others were female. More than half of the respondents do online shopping very frequently and use Facebook as their mode of shopping. About $55 \%$ of the respondents prefer to buy clothing products from online. An interesting finding of the study showed that most people do not prefer to buy expensive products from online. Only $23 \%$ of people prefer to buy expensive products from online. However, $66 \%$ people said that they prefer online shopping over traditional shopping.

\title{
Recommendation
}

Do you think the online shopping scene in Bangladesh can be improved more?

133 responses

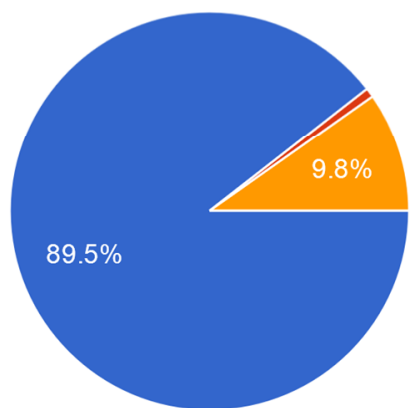

\author{
Yes \\ No \\ Maybe
}

The delivery issues with online shopping can be solved if more professional delivery men are hired. Moreover, they can make use of courier services that delivery product within short span of time. Another issue was the mismatch of delivered products with the products that are displayed online. In this case, businesses will have to make sure that customers get the exact products that they have ordered. This is important because, when customers do not get the product, they order can lead to trust issues which may give them hard time to retain their customers. In addition, most people are not confident with buying expensive from online sites, so businesses must find strategies to tackle the situation. Firstly, they can offer the option of paying for expensive products in installments. Most importantly, when online sites sell expensive products, they must be exclusive that is the products should only be available at their sites which will give consumers no other options rather than buying it from their sites. According to the study, people also said that they use Facebook as the platform for their online purchase and very few of them use applications for online purchase.

How open are you to buying expensive products from online shops?

135 responses

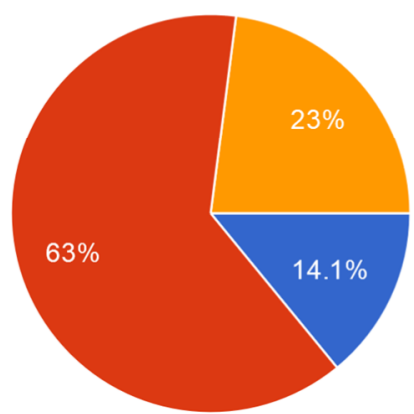

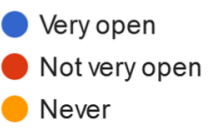

Never

To increase the sales through applications businesses can make their applications more user friendly. The study also says that the majority of the people think that the online shopping scene in Bangladesh is not well developed. To satisfy their needs, the online businesses of Bangladesh can adopt the strategies used by big online businesses such as Amazon. Again, many consumers of online market complain of not feeling secure with online purchase. So, business must make their applications and other Medias secures by securing personal information and contacts of user. This will make consumer feel secure and in return online businesses will flourish. An important step that can be taken by online businesses is to include elderly people in their consumer list. Elderly people usually invest more on buying products so; making them feel comfortable with online shopping can be of enormous benefit. The issues that came up according to the study can be solved to some extent if such measures are applied. 


\section{Conclusion}

Online shopping is a growing sector in Bangladesh and the growth is still positive which clearly indicates that the future prospects of online shopping in Bangladesh is flourishing. The online shopping has already captured consumers from almost every age group and genders. As a result, the numbers of online shopping websites are increasing every day. Traditional shops are also opening their online sites to walk with the trend. Moreover, the websites are user friendly too. However, the elderly people are still highly dogmatic to traditional shopping.

\section{References}

1. Haque.R https://www.thedailystar.net/lifestyle/spotlight/online-shopping-1412578.

2. Rogovsiky, V. (2018, Nov 28), How Technology Could Revolutionize Online Shopping In The Near Future. Retrieved from https://www.forbes.com/sites/forbestechcouncil/2018/11/28/how-technology-couldrevolutionize-online-shopping-in-the-near-future/\#2cd7d7165117

3. Brown, M., Pope, N. \& Voges, K., (2003) Buying or browsing?: An exploration of shopping orientations and online purchase intention. European Journal of Marketing, 37(11/12), pp.1666

4. Shahrukh. S (2019, December 4) Future of e-Commerce in Bangladesh. Retrieved from https://www.observerbd.com/details.php?id=204117

Author's biography;

1. Ms. Fabiha Enam (Senior lecturer and Assistant proctor of Brac University, Bangladesh ): She passed her Msc in International Business \& Entrepreneurship from University of Glasgow, UK in 2010-2011. She obtained her Bachelors in Business Administration from BRAC University (Major in Finance and Marketing) in 2009. She has research interest in International Business, Marketing, E-Marketing etc. She has already published several journals in International Journals.

2. Tanjila Rahman: She is a current student of BRAC UNIVERSITY, Bangladesh. She is Studying Bachelor of Business Administration at BRAC UNIVERSITY. She is doing her major in Marketing \& Human resource management. She currently works at BIZBEE ( BRAC UNIVARSITY Business Club). She has Research interest in Marketing (Advertising activities, consumer behavior, consumer perception, market segment), Digital marketing ,Human Resource Management. She is working on it. She is also very active on different extra-curricular activities.

3. Mehedi Hasan Tanvir : He is a student and completing his Bachelor Of Administration at BRAC UNIVARSITY, doing double major on Marketing and Human Resource Management. He currently works at BIZBEE ( BRAC UNIVARSITY Business Club) as a Director. He is very passionate about marketing research like consumer perception, buying decision, digital marketing, market segmentation etc. He is also very active on social activities and different extra-curricular activities. 